\title{
Nuwe verwikkelinge in die elektromagnetiese, nie-destruktiewe toetsing van staalmynhystoue
}

G. L. Bredenkamp* en N. T. van der Walt

Laboratorium vir Stelsels, Randse Afrikaanse Universiteit. Posbus 524, Johannesburg 2000

Onrang 17 Oktober 1989; acnvar 22 Jamuarie 1990)

\section{UITTREKSEL}

Die betroubaarheid van mynhystoue is van kardinale belang vir die veiligheid van personeel en vir die handhaning v'an produktiwiteit op mine.

Potensiële breuke moet vooruit voorspelhar wees met 'n minimum ontwrigting ran mynbou-aktwiwiteite. Sowel hestaande as nuwe tegnieke wat ontwikkel is, word gë̈ntegreer in 'n enkele kompakte stelsel om al drie tersacklike touparame'ers, t.w. deursneeoppervlakte, antal gebreekte drade en elektriese kontak tussen die drade, gelykt!dig, en met die tou in situ, op 'n nie-vernietigende elektromagnetiese metode te meet.

Elektromagnetiese teorieë is ontwikkel wat mune insigte verskaf in die werking van sulke stelsels, wat dan toegepas word in "n "magneetkop", opgehou ait gesofistikeerde permanente magnete en saaltipe meetspoele, wardeur die tou heveeg. Hierdeur word 'in elegante oplossing wir 'n prohleem, wat sedert die hegin van die mynhedryf hestan, gehied.

\section{ABSTRACT}

The reliability of hoist ropes is of utmost importance for the safety of personnel and for maintaining productivity in mines.

*Outeur aan wic korrespondensie gerig kan word. 
Potental fractures should be predicted in advance, hut with the minimum distuprion of mining activiries. Existing as well as new/y developed techniques are integrated into a single compact spstem to measure the three most relevant rope parameters, which are: cross sectional area, momber of hroken wires and the ohmic contact hetween wires. These parameters are measured simultaneous/y, in situ, in a non destructive manner.

Electromagnetic theories have been developed which provide new insight into the working of such systems and were applied in the construction of a magnetic test head, comprising sophisticated permanent magnets and saddle type search coils, through which the rope is passed. This system provides an elegant solution to a problem which has existed since the beginning of the mining industry.

\section{INLEIDING}

Mynhystoue se diensbaarheid is te alle tye van die allergrootste belang, nie net uit 'n veiligheidsoogpunt nie, maar ook uit 'n produksic- en dus ook ekonomiese oogpunt. Gereelde fisiese ondersoek, met nie-destruktiewe toetstegnieke is dus noodsaaklik.

Omdat myntoue deurgaans van ferromagnetiese materiaal gemaak word, word elektromagnetiese toetsmetodes aanbeveel. Die welslae wat hiermee behaal is, word hier bespreek. ${ }^{5}$

Defekte wat algemeen in mynhystoue voorkom, is:

(i) Plastiese deformasie

(ii) Slytasie

(iii) Meganiese skade

(iv) Korrosie (roes)

(v) Metaalvermoeiing deur vibrasie

(vi) Kinkels

Die Suid-Afrikaanse mynbedryf beskou dit as noodsaaklik om die volgende touparameters, in situ, oor die hele toulengte, te meet:

(i) veranderinge in staaldeursneeoppervlakte;

(ii) veranderinge in die laterale kontakpatroon tussen die drade:

(iii) die opsporing van gebreekte drade.

As hierdie drie parameters so onafhanklik as moontlik van mekaar gemeet kan word, is dit moontlik om defekte en potensiële defekte in 'n tou vroeg op te spoor om katastrofes te voorkom en om redelik noukeurig te bepaal wanneer 'n tou aan die einde van sy bruikbare leeftyd gekom het.

Veranderinge in staaldeursneeoppervlakte en veranderinge in die laterale kontakpatroon tussen die drade van die tou word tot dusver met die sg. wisselstroommetode (WS-metode) ${ }^{1.2}$ gemeet en gebreekte drade word met die sogenaamde gelykstroommetode (GSmetode) $)^{3}$ opgespoor.

Die goudafdeling van die Anglo America Myngroep alleen toets tans jaarliks tussen vier-en vyfmiljoen meter tou volgens hierdie twee metodes.

Myntoue word egter steeds dikker en omdat die penetrasie van die magneetveld in die tou ontoereikend is, ${ }^{4}$ het die WS-metode ondoeltreffend geword. Daar het verder ook, weens operasionele en ekonomiese redes, die behoefte ontstaan om die drie touparameters terselfdertld met dieself de instrument, maar onafhanklik van mekaar, te meet.

'n Toetskop met permanente magnete waarmee lg. behoefte bevredig word, word hier beskryf.

\section{Die magneetkop}

\subsection{Konstruksie}

Soos in die foto van fig. 1 en die skets van fig. 2 getoon, bestaan die magneetkop hoofsaaklik uit:

(a) vier stapels neodinium-yster-boor permanente

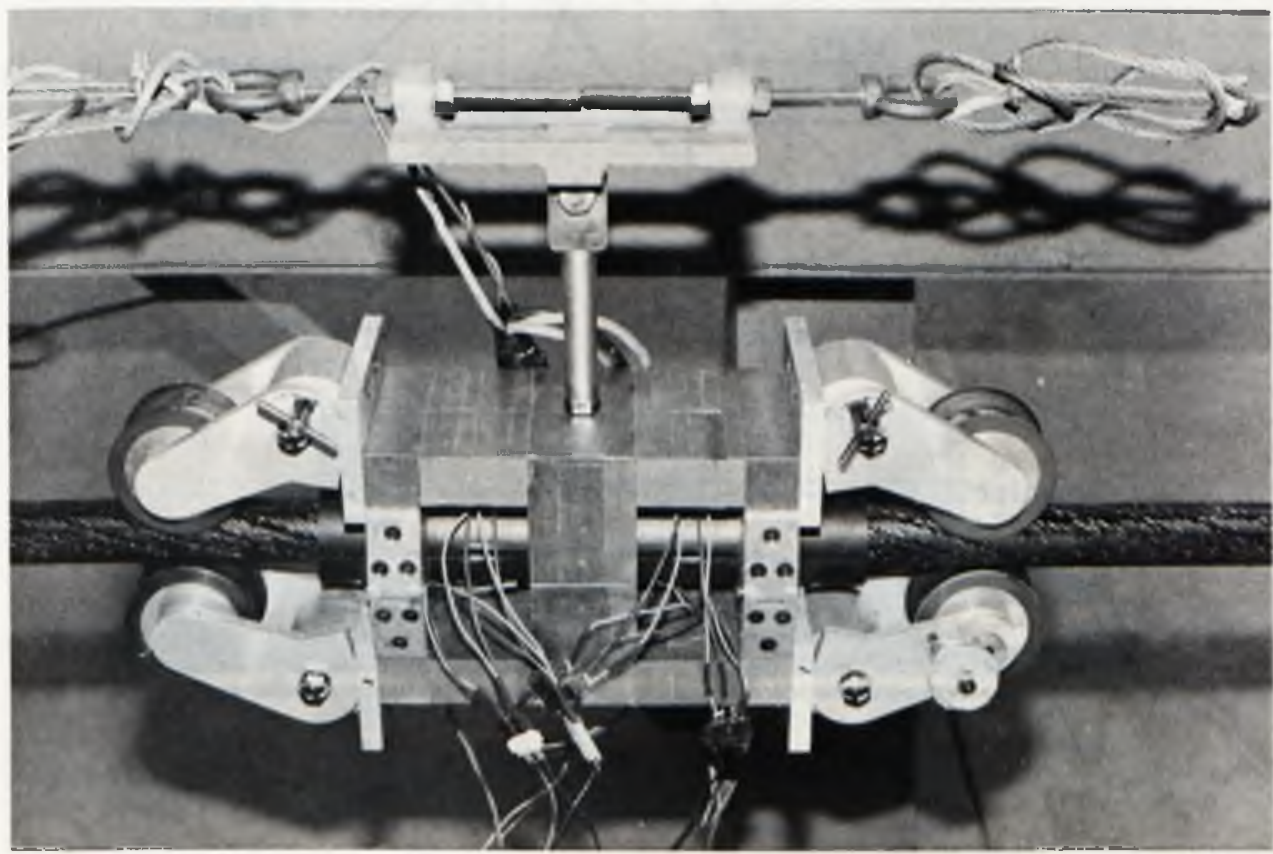

Figuur I: 'n Eksperimentele magneetkop op 'n toetstou. 
malgnete;

(b) drie stelle sagtestalalpoolstukke;

(e) verskeie sg. "saalspoele" waarmee vloedveranderings gemeet word; en

(d) vier rollers of wiele watrmee die tou t.o.v. die magneetkop gesentreer word.

Die magneetkop is in twee helftes verdeel sodat dit oopgemaak kan word om om 'n tou geplatas te kan word en om dit te verwyder na afloop van die toetse.

\subsection{Funksie}

Die doel van die magneetkop is eerstens om die tou. soos dit deurbeweeg, te magnetiseer volgens dic kromme van fig. 3. Soos enige touseksie deur die magneetkop beweeg, verander die magnetisering daarvan vanaf $\mathrm{B}=0$ deur die versadigingswatarde tot by $\mathrm{B}_{\mathrm{mak}}$ en daarna terug deur $\mathrm{B}=0$ lot by $-\mathrm{B}_{\text {mak }}$, walarop dit dan weer terugval na $\mathrm{B}=0$ walar die touseksic an die agterkant van die magneetkop uitbeweeg.

Hierdic magnetiseringskromme is nodig om al die touparameters, hierbo genoem. onathanklik van mekalar te meet.

Saalspocle op die magneetkop word gebruik om dic vloedverandering in dic tou, by die punte waar $B= \pm B_{m i k}$, en walar $B=0$, in die middel ran dic magneetkop, te meet.

Vloedveranderings by $\mathrm{lg}$. punte stel die gebruiker in staat om, onathanklik van mekaar. deursneeoppervlakteveranderinge, gebreckle drade en veranderinge in geïnduseerde werwelstrome op te spoor, walt op verskillende foute in die tou dui.

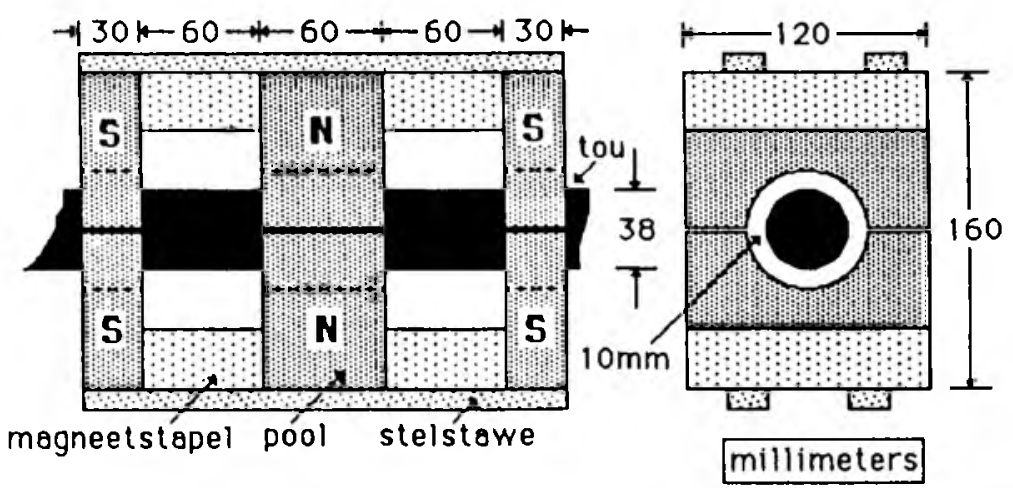

Figunr 2: Simmetriese saumgestelde neodimium-1'sterhoor-magneetkop.

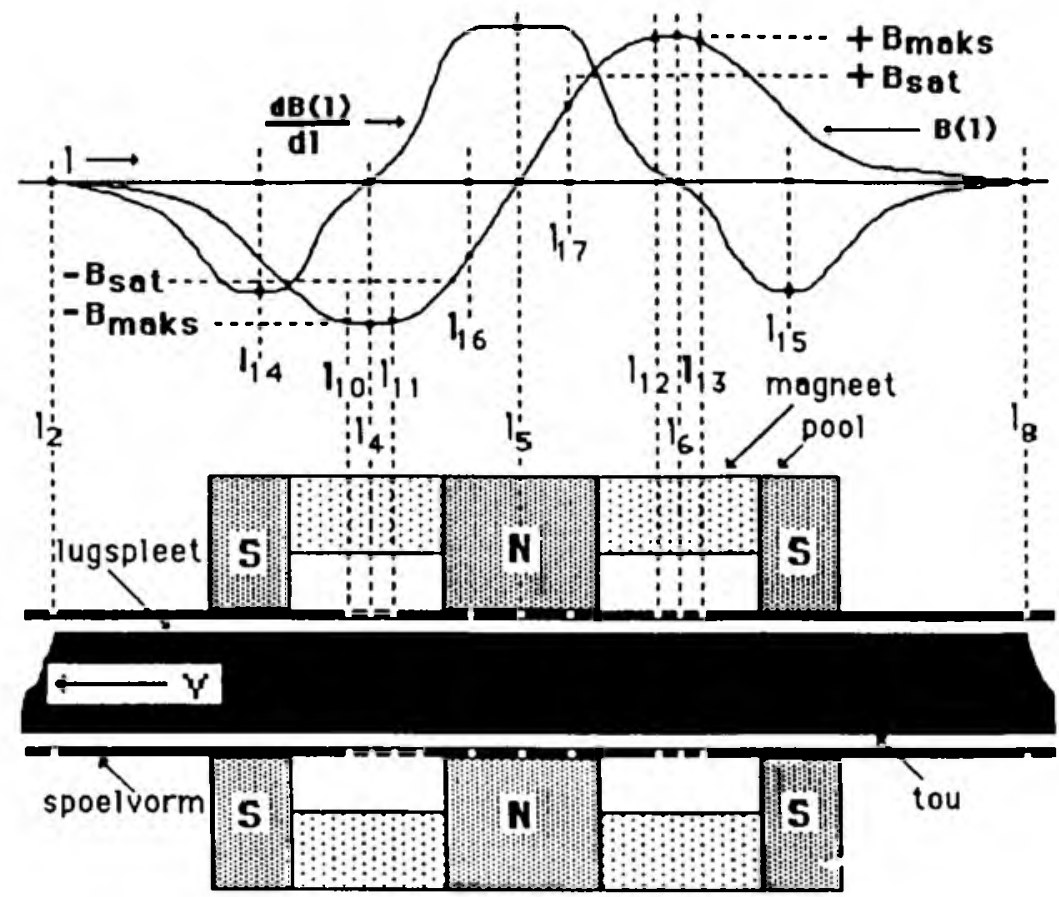

Figunr 3: Dic magnetiseringskromme van dic tou. 


\section{Meet van magnetiese vloed}

3.1

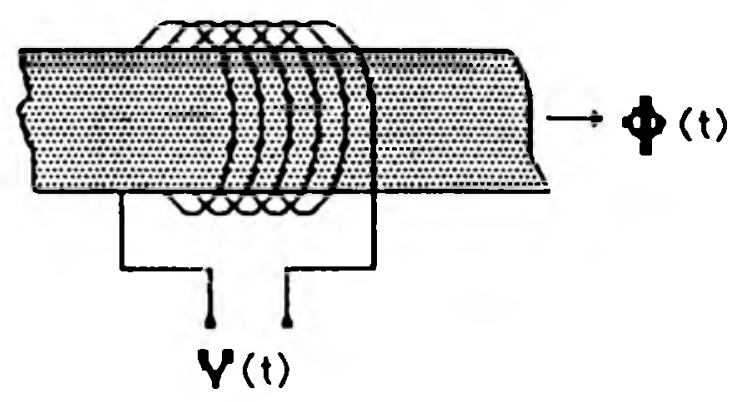

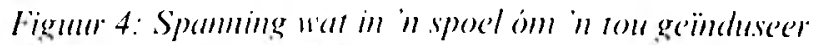

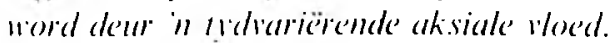

Indien in spoel van $\mathrm{N}$ draaic om die toetstou geplats word. soos skematies in fig. 4 uitgebeeld. sal enige vloedverandering $\Delta \Phi$ in die tou, wal tussen $t_{1}$ en $t_{2}$ plaasvind, gegee word deur:

$$
\Delta()=\frac{1}{N} \int_{t_{1}}^{t_{2}} V(t) d t
$$

walar V(t) dic geinduseerde spanning in die spoel is.

$\Delta$ (D word m.b.v. 'n elek troniese integrator verkry, en indien dit teen tyd op "n registreerder gestip word, sal hierdic kromme van $\Delta \Phi$ 'n aanduiding wees van die vloedverandering langs die tou al, soos die tou deur die spoel beweeg.

\subsection{Saalspocle}

Konvensioncle sirkelvormige meetspoele, veral die met 'n veelvoud van dratic, is nic met die magneetkop wat oopmaak vir plasing om die tou, versoenbaar nie. Hicrdie probleem word met die gebruik van pare identiese saalspocle elk met $N$ dratic, soos in fig. 5 getoon, opgelos.

Indien die terminale $H$ en J verbind word, sal die spanning, gemeet tussen terminale $A$ en $R$, identies wees aan dic van twee sirkelvormige spoele, geplaas by posisies $I_{x}$ en $I_{y}$. elk met $N$ drataie en in serie teenwerkend met mekalar verbind.

\section{Die meet van touparameters}

\section{I Deursneeoppervlakteverandering}

Die vloedveranderinge in die tou waar die tou diep in magnetiese versadiging is, is slegs 'n aanduiding van deursneeoppervlakteverandering en word nie deur veranderings in kontak lussen die drade beïnvloed nie.

Vir hierdie doel kan een kant van die saalspoele dus in die gleuf by $I_{4}$ geplatas word (fig. 3), terwyl die anderkant by 'n neutrale posisic - walar daar geen vloedverandering kan plaasvind nie, soos bv. by $l_{2}-$ geplaas kan word. Alternatiewelik kan dieselfde resultat by gleuwe $I_{6}$ en $I_{8}$ verkry word. Hierdie twee moontlikhede word meetstelsel 1 genoem. Die verandering in oppervlakte

$$
\begin{aligned}
\Delta A(t)= & \frac{1}{N B_{\text {maks }}} \int_{0}^{t} V_{2}(t) \cdot d t= \\
& \frac{1}{N B_{\text {maks }}} \cdot \int_{0}^{1} V_{t, 8}(t) \cdot d t \ldots .
\end{aligned}
$$

'n Verdere moontlikheid is om die saalspoele tussen $I_{4}$ en $l_{0}$ te plaas wat

$$
B\left(I_{6}\right)=-B\left(I_{4}\right)=B_{\text {miks }}
$$

In dié geval is $\Delta A(t)=\frac{1}{2 N B_{\text {mahs }}} \int_{0}^{t} V_{40}(t) \cdot d t$

Dit word meetstelsel 2 genoem.

Aangesien $\mathrm{V}_{46}(\mathrm{t})=2 \mathrm{~V}_{42}(\mathrm{t})$ is lg. meetstelsel twee maal so sensitief as meetstelsel I.

Meetstelsels I en 2 is herhaaldelik getoets deur telkens 5 lengtes van $2,12 \mathrm{~mm}$ deursnee draad, elk $300 \mathrm{~mm}$ lank, lateraal aan die tou te heg, soos in fig. 6 getoon. Elke byvoeging het 'n deursneeoppervlakteverandering van $2.47 \%$ verteenwoordig.

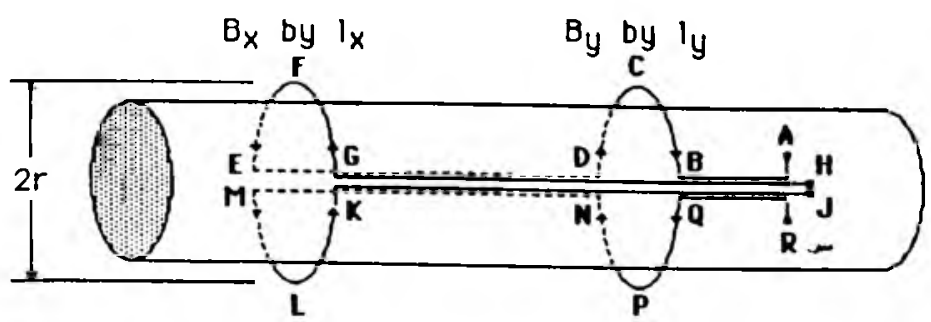

Figuar 5: 'n Paar saalspoele. 
Fig. 7(a) en (b) wys die golfvorms wat verkry is in die geval waar $\frac{\Delta \mathrm{A}}{\mathrm{A}}=4,9 \%$, d.w.s. vir 10 drade.

Die trap in sowel die opgaande as die af gaande llank van die golfvorm in meetstelsel 2 is toe te skryf aan die aksiale verplasing tussen die saalspoelkante, d.w.s. die afstand tussen $I_{4}$ en $I_{6}$.
Hierdie trap is afwesig in fig. 7(a), alangesien net een kant van die saalspoele (by $I_{4}$ ) aktief is. In fig. 8 word die gemete vloedverandering $\Delta(\Phi)$ gestip.

Die gemiddelde helling van hierdie kromme is 2,27 tesla teenoor die gemete maks. vloeddigtheid van 2.29 tesla. Die meting is dus binne die $1 \%$-grens noukeurig.

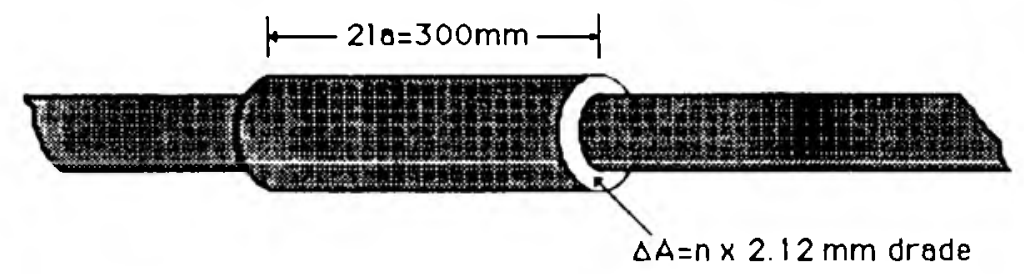

Figuar 6: Simulasie van densneeoppervakteverandering.
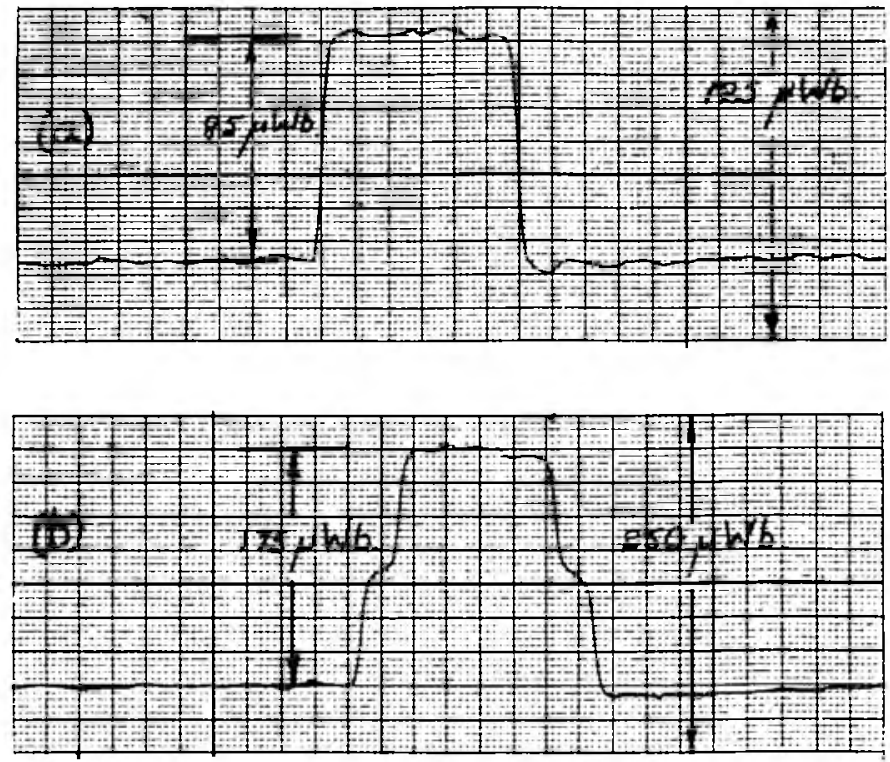

Figulu 7: (a): $\triangle \Phi$ rloedgolfrorm met meetstelsed I. (h): $\triangle \Phi$ bloedgolfrorm met meetstelsel ?.

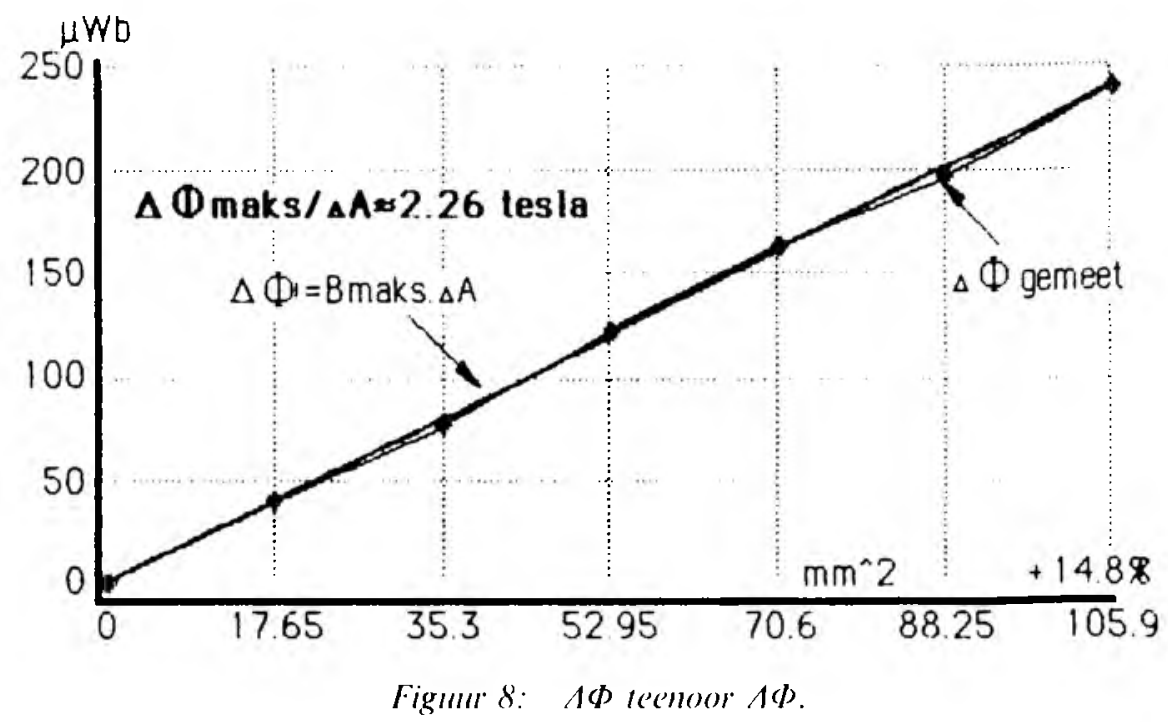




\subsection{Gebreckle drade}

4.2.1 'n (jebreek te draid vorm 'n magnetiese dipool met magnetiese moment

$$
\mathrm{M}=\mathrm{B} \mathrm{a}\left(2 \mathrm{I}_{\mathrm{i}}\right)=B \mathrm{Bu}_{\mathrm{a}}
$$

walar $a=$ deursneeoppervlakte van die draad.

$21_{a}=$ aksiale lengte van die breuk of die afstande tussen die gebreekte ente, en

$v_{d}=$ volume van die breuk.

Dit kan getoon word dat wanneer salalspoele in die opspoor van breuke gebruik word, die spanningspick "n optimum vir "in breuk enige plek in die tou sal wees, wanneer die lengle van die sialspoele

$21,=0.8$ r.

en walar $r$ die straal van die salalspoele is.

Verder word die maksimum sensitiwiteil verkry watar $B=B_{\text {mak }}$.

Die saalspoele vir hierdie meting word dus in gleuwe gesimuleer word deur drade aksialal agter mekalar op die tou vals te maak, met aksiale gapings tussen die ente.

Fï. 9 wys die spanningspulse walar:

$$
\begin{aligned}
& B_{\text {m.th }}=2,29 \text { teslat, } \\
& a=16 \mathrm{~mm}^{2} \text {. } \\
& \mathrm{v}=2 \text { meter per sekond, } \\
& \mathrm{N}=40 \text {, } \\
& 21 \text {, }=22 \mathrm{~mm} \text {. } \\
& \mathrm{r}_{4}=29 \mathrm{~mm} \mathrm{cn}
\end{aligned}
$$

Fig. 10 wys dieselfde, malar vir

$$
\begin{aligned}
\mathrm{a} & =3.53 \mathrm{~mm}^{2} \\
\mathrm{v} & =1 \text { meter per sekond en } \\
2 \mathrm{l}_{\mathrm{a}} & =1,2,3,4 \mathrm{en} 5 \mathrm{~mm} \text { onderskeidelik. }
\end{aligned}
$$

Die gemete pulse vergelyk goed met die berekende walardes.

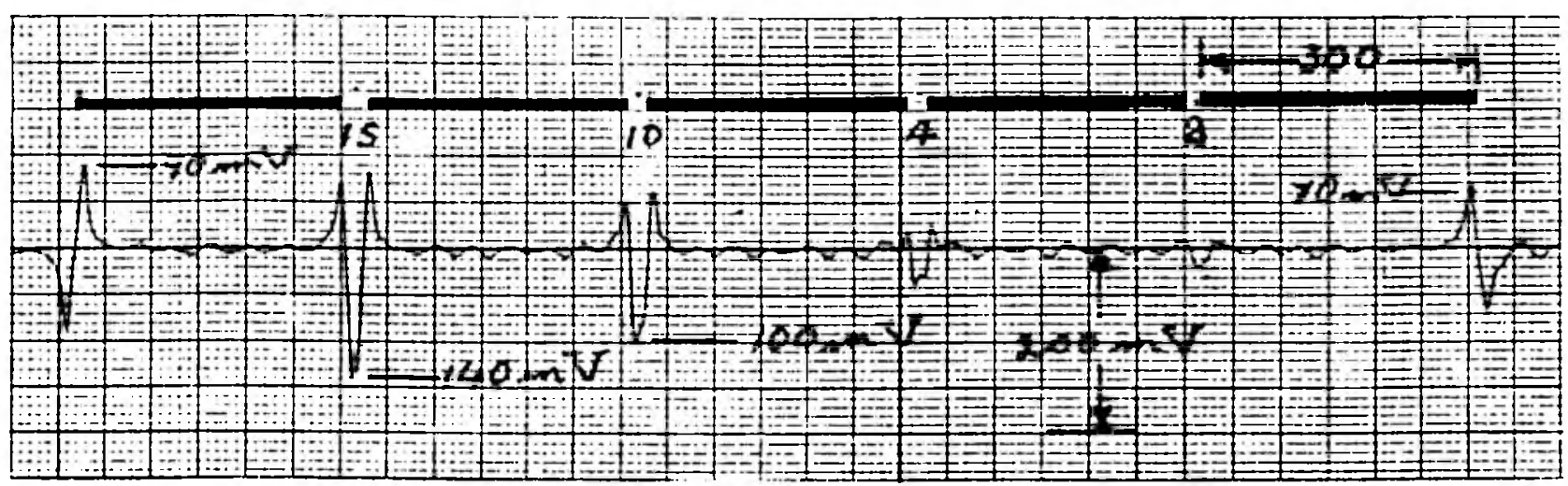

Figuur 9: Gehreektedraad-dipoolspanningspulse.

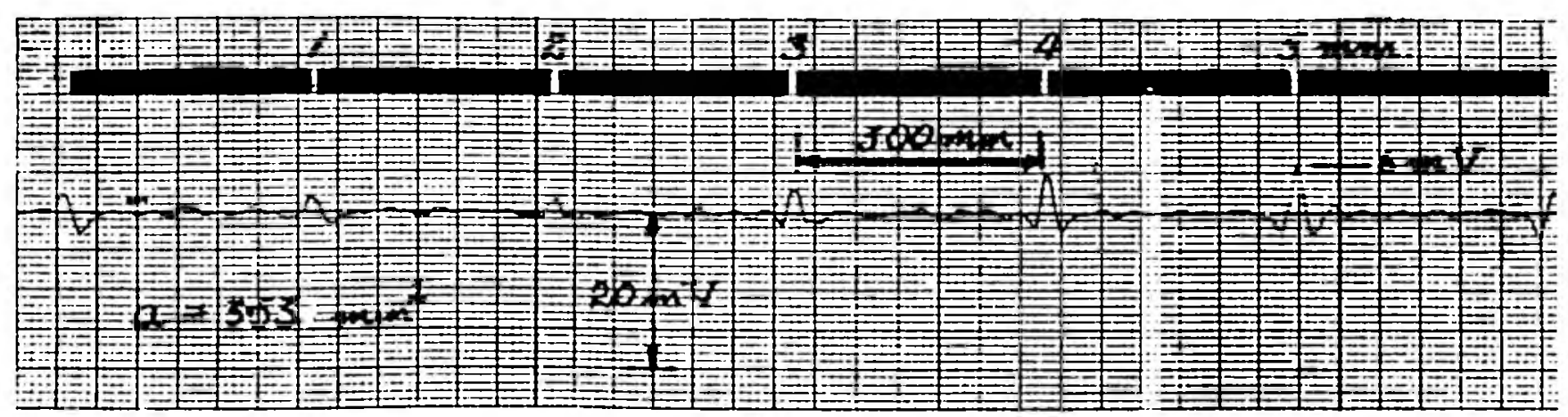

Figuur 10: Gehreektedraad-dipoolspanningspulse.

$l_{10}$ en $l_{11}$ of $l_{12}$ en $l_{13}$ (fig. 3) geplaas. Vir 'n breuk naby die tou-oppervlakte is die piekamplitude van die spanningspuls sodoende verkry:

$$
\mathrm{V}_{\mathrm{r}}=\frac{2.4}{\mathrm{r}_{\mathrm{s}}^{2}} \vee \mathrm{NB}_{\text {muks }} \text { va volt }
$$

waar $v$ die snelheid van die tou in $\mathrm{m} / \mathrm{s}$ is. Vir 'n kort breuk in die middel van die tou is

$$
\mathrm{V}_{\mathrm{p}}=\frac{1.64}{\mathrm{r}_{\mathrm{s}}{ }^{2}} \mathrm{vN} \mathrm{B}_{\text {maks }} \text { va volt }
$$

Gebreekte drade op die tou se omtrekoppervlakte kan

\subsubsection{Tougeruis}

By dáárdie plekke waar die drade van die tou met mekaar kruis, word mettertyd kepe in die drade gesny.

"Tougeruis" word gedefinieer as die gesamentlike meetbare effek van al die kepe in die tou. Hierdie effek neem toe met die tou se werkende ouderdom.

Uit fig. 10 word afgelei dat tougeruis vir daardie bepaalde meting ongeveer 1 millivolt is.

As $\mathrm{V}_{\mathrm{g}}$ die geruisamplitude is, is die minimum meetbare gebreektedraad-dipoolvolume in die middel van die tou: 


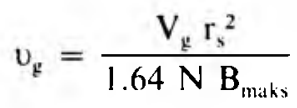

Vir die meting van fig. 10 is $v_{g} \approx 4 \mathrm{~mm}^{3}$.

\subsection{Kontakveranderinge}

Die magneetkop is so ontwerp dat dié dele van die tou wat op enige oomblik tussen die suidpole en die sentrale noordpool van die magneetkop is, magneties versadig is, en dat die vloeddigtheidsomkering van negatiewe versadiging na positiewe versadiging oor die aksiale lengte, $2 l_{\mathrm{N}}$, van die sentrale noordpool plaasvind.

Oor die lengte $2 \mathrm{I}_{N}$ is die vloeddigtheidsgradiënt

$$
\begin{aligned}
\frac{\mathrm{d} B}{\mathrm{dl}} & \approx \frac{\mathrm{B}_{\mathrm{s}}}{\mathrm{I}_{\mathrm{N}}}=50 \text { tesla per meter, en die } \\
\text { permeabiliteit } & \\
\mu_{\mathrm{c}} & \approx 1,98 \times 10^{-3} \text { tesla meter per ampere. }
\end{aligned}
$$

Wat werwelstroomvloed en die meet van kontak veranderinge tussen die drade betref, is dit slegs hierdie deel van die tou wat van belang is.

As werwelstroomvloed met saalspoele tussen $I_{5}$ en $\mathrm{I}_{2}$ (of $\mathrm{I}_{5}$ en $\mathrm{I}_{8}$ ) van fig. 3 met die metode en apparaat van fig. 7 gemeet word, is so 'n meting onathanklik van deursneeoppervlakteveranderinge as

$$
\mathrm{B}_{\mathrm{aks}}=0 \text { by } \mathrm{l}_{\mathrm{s}}
$$

Die presiese plek watar $B_{a k \text {, }}=0$ is, is egter 'n eksponensiële funksie van die toetssnelheid. As daar op in toetssnelheid van (sê) 2 meter per sekonde gestandardiseer word, word die presiese posisie van $1_{5}$ eksperimenteel vasgestel deur die salspoele aksiaal te verskuif sodat geen werwelstroomvloedverandering gemeet word as gevolg van in kunsmatige deursneeoppervlak teverandering nie.

So " $n$ verskuiwing, $\Delta \mathrm{l}_{5}$, van die sentrale posisic af, is tipies ongeveer $6 \mathrm{~mm}$ by 'n toetssnelheid van 2 meter per sekonde.

Kontakwerwelstrome in 'n tou is 'n soortgelyke elfek in die tou as "huideffek" in "n wisselstroomdraende draad: deur die werwelstroomvloed wat dit opwek. word die vloeddigtheidsdistribusie oor die deursneeoppervlakte van die tou versteur, afhangende van die (onbekende) "kontakkonduktiwiteitsdistribusie".

As welwelstroomvloed by $I_{5}$ gemeet word, kan datar gewys word dat die kontakwerwelstroomvloed

$\phi_{k}=2 B, A\left(\frac{v T_{k}}{I_{N}}\right)\left(i-e^{V_{h}}\right) \int_{0}^{1} x\left[F_{h}(x)\right] d x$

watr $B$, die versadigingsvloeddigheid van die tou.

A die deursneeoppervlakte van die tou.

$\mathrm{T}_{\mathrm{K}}$ die "kenmerkende kontakwerwelstroomtydkonstante",

$\mathrm{v}$ die toetssnelheid.

$x$ die genormaliseerde stral van die tou

en $F_{h}(x)$ die "kenmerkende konlakvloeddigtheidsdistribusiefunksic" is.

$T_{k}$ word gedefinieer as

$$
\mathrm{T}_{\mathrm{k}}=\frac{\Lambda}{\pi} \mu_{\mathrm{r}} \mathrm{g}_{\mathrm{h}}
$$

waar $g_{h}$ op sy beurt as die "kenmerkende kontakkonduktiwiteit" van die tou gedefinieer word.

\section{1}

$T_{k}$, (en dus $g_{k}$ ) en $\int x\left[F_{h}(x)\right] d x$ kan deur meting ()

bepaal word. hoewel $F_{h}(x)$ self onbepaalbaar is.

Vir die toetstou is

$\mathrm{T}_{\mathrm{K}} \approx 60$ millisekondes

$\mathrm{g}_{\mathrm{h}} \approx 0,12 \times 10^{\circ}$ siemens per meter en

$$
\int_{0}^{1} x\left[F_{h}(x)\right] d x \approx 0,085
$$

$$
\text { Dus as } \begin{aligned}
B_{\Delta} & =1.5 \text { tesla, } \\
A & =717 \mathrm{~mm}^{2}, \\
21_{N} & =60 \mathrm{~mm} \\
v & =2 \text { meter per sekond, is }
\end{aligned}
$$

\section{$\phi_{\mathrm{h}}=162$ mikroweber}

As daar "n verandering in "kontak" is, is daar veranderinge in beide $g_{h}$ (en dus $T_{K}$ ) en $\Gamma_{h}(x)$. met 'n gevolglike meetbare verandering. $\Delta \Phi_{k}$, in die werwelstroomvloed, watar

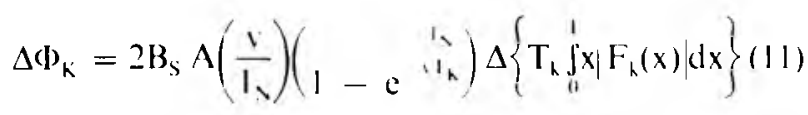

\section{Laboratoriumtoctse}

Laboratoriumtoetse op die toetstou is in die AAEL Toutoetsnavorsingsfasiliteil gedoen. Fig. 11 toon dic gelyktydige meling van kontakveranderinge (lig. 11 (a)) die opsporing van gebreekle drade (fig. 11 (b)) en die meet van deursneeoppervlakleveranderinge (tig. $11($ c)) teen in toetssnelheid van 2 meter per sekonde. In die geval van die meel van kontakveranderinge en deursneeoppervlakteveranderinge he die saalspoele 20 draaie gehad en in die geval van die opsporing van gebreekte drade. 40 draaic

Mel verwysing na fig. 11 , as die magneetkop van regs na links oor die tou gesleep word, is die kontakmeetsein met ' $\mathrm{n}$ aksiale afstand van $\Delta \mathrm{l}_{5}=6 \mathrm{~mm}$ (of $0.3 \mathrm{~mm}$ op lig. 11) ten opsigte van die deursnecoppervlakle meetsein met meetstelsel (ii), vertraag.

As die gebreckte dratde met die salalspoele tussen $l_{11}$ en $I_{11}$ van fig. 3 opgespoor word, is dic deursneeoppervakteverandering meetsein, gemeel met meetstelsel (ii), met 'n aksiale afstand van $\left(l_{\sqrt{ }}-l_{5}\right)=60 \mathrm{~mm}$ (of 3 mm op lig. 1 l) ten opsigle van die gebreckte drademeetsein vertratag.

As die deursnecopperviakleveranderinge met meetstelsel (i) en saalspoele tussen $1_{2}$ en $l_{4}$ van fig. 3 gemeel word, is hicrdie meetsein aksialal gelyktydig met die 
gebreektedratadmeetsein soos hierbo, en is die kontakverandering meetsein aksiaal met 'n al'stand van $\left(I_{+}-I_{5}\right.$ $\approx 66 \mathrm{~mm}$ vertrailg.

Omdat net een integrator vir vloedmetings beskikbatar was, is die gebreckte drade en deursnecoppervlakteveranderinge eers gelyk tydig gemeet en direk daarna is die kontakveranderinge teen dieselfde loetssnelheid gemeet

Vir die metings van fig. 11 is anomaliee van kontakieranderinge, gebreek te drade en deursneeoppervlakteveranderinge kunsmatig op en in die tou gesimuleer.

Met verwysing nat fig. 11:

Punt A: Hier is die toubesk rywing met "n vlam rooiwarm gemalak sodal dit dáár effens gerek het deur dic 10 ton-trekspanning op die tou. Die teer in die tou het weggesmelt. Hier was dalar dus:

(i) 'n deursnecoppervlakteverandering:

(ii) 'n kontakterandering tussen die drade van die tou en

(iii) 'n simulasie van 'n massiewe konsentrasic van gebreekte drade.

Hierdie kunsmalig gesimuleerde anomalie moet dus deur al drie meetseine gemeet word soos op fig. 11 gesien kan word.

Punt B: Hier is 'n dun nylonskyfie, met 'n aksiale lengte van ongeveer $20 \mathrm{~mm}$, tussen die drade van die tou ingeforseer sodat dit nie van buite sigbaar was nie. Hier was dus slegs in kontakverandering en geen gebreckte drade of deursneeoppervlakleverandering nie. Hierdie anomalie moet dus net deur die kontakmeetsein opgespoor word soos in fig. 11 gesien kan word.

Punt C: Hier is 'n koperring. $10 \mathrm{~mm}$ link en $0.5 \mathrm{~mm}$ dik, styf om die tou gesoldeer.

Hiér is dus ook geen gebreckte drade of deursneeoppervlakteverandering nic. Daar vloci egter 'n werwelstroom in die koperring, wat die werwelstroomvloed in die tou vermeerder.

Hierdie werwelstroomvloedvermeerdering moet dus slegs op die kontakmeetsein verskyn, soos op fig. Il gesien kan word.

Punt D): Hier is die tou "n harde hou met 'n $2 \mathrm{~kg}$ hamer toegedien.

Die kontak tussen die drade van die tou is walarskynlik versteur, maar geen drade is gebreek of die deursnecoppervlakte verander nie. Die effek op die drie meetseine is diesclfde as vir B.

Punt E-I: Tussen hierdie punte is $5 \times 300 \mathrm{~mm}$ lange dubbele toudrade, elk met 'n deursinee van $3.18 \mathrm{~mm}$, aksiaal op die tou vasgemalak. met aksiale gapings valn $1,2,5 \mathrm{cn} 10 \mathrm{~mm}$ tussen die 5 lengtes.

Deursneeoppervlaktevermeerdering van 16 $\mathrm{mm}^{2}$ asook gebreektedraaddipole met in

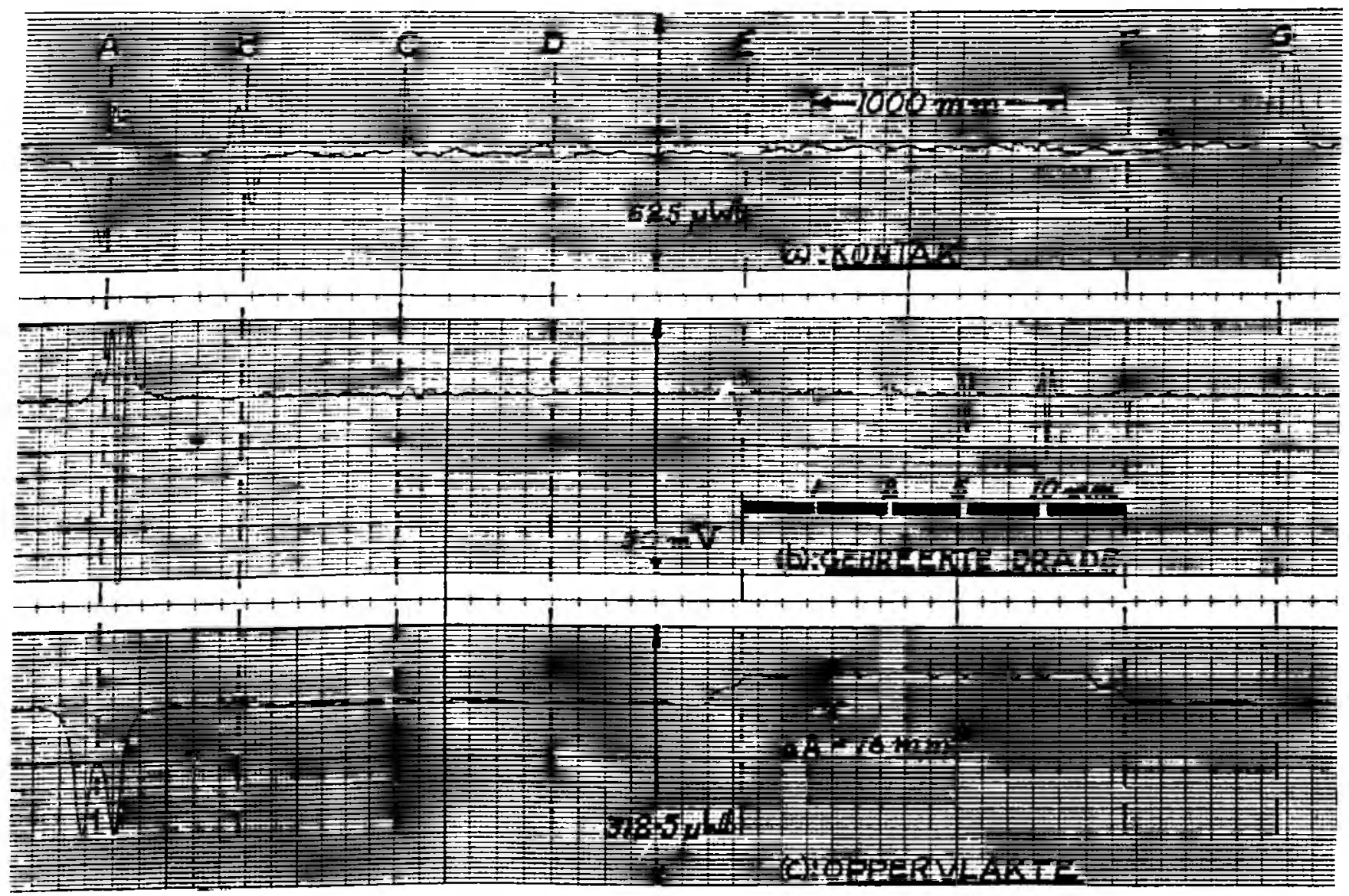

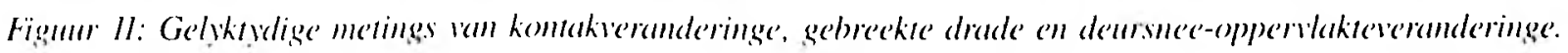


oppervlakte van $16 \mathrm{~mm}^{2}$ en aksiale lengtes van onderskeidelik 1, 2, 5 en $10 \mathrm{~mm}$ (d.w.s. dipoolvolumes van onderskeidelik 16. 32. 80 en $160 \mathrm{~mm}^{3}$ ) word dus gesimuleer.

Daar is geen gesimuleerde kontakverandering nie en fig. II wys dat slegs die gebreekte drade opgespoor en die deursneeoppervlaktevermeerdering noukeurig gemeet is. Op die oppervlaktemeetsein kan die effek van die gebreckte drade net-net gesien word. (Dic dubbel pulsies van dic 5 en 10 $\mathrm{mm}$ breuke is te wyte aan meetstelsel 2.)

Punt G: 16 late aluminiumfoelie. elk $0.0254 \mathrm{~mm}$ dik. is oor in aksiale afstand van $125 \mathrm{~mm}$ styf om die tou gewen. Hiér was daar ook geen gesimuleerde gebreekle drade of deursneeoppervlakteverandering nic, en is die effek op die drie meetseine dieselfde as vir $B . C$ en D.

Fig. Il is die eksperimentele bewys dat 'n metode suksesvol ontwikkel is om deursneeoppervlakteveranderinge en laterale kontakveranderinge tussen die drade van 'n staaltou en gebreekte drade gelyktydig met dieselfde instrument, maar onathanklik van mekaar. te meet en/of op te spoor.

\section{Veldtoctse}

Die heel eerste veldtoetse met so 'n eksperimentele toutoetsstelsel is op ses 200 meter lange Langslagdrichoekbundeltoue op New Denmark koolmyn uitge-
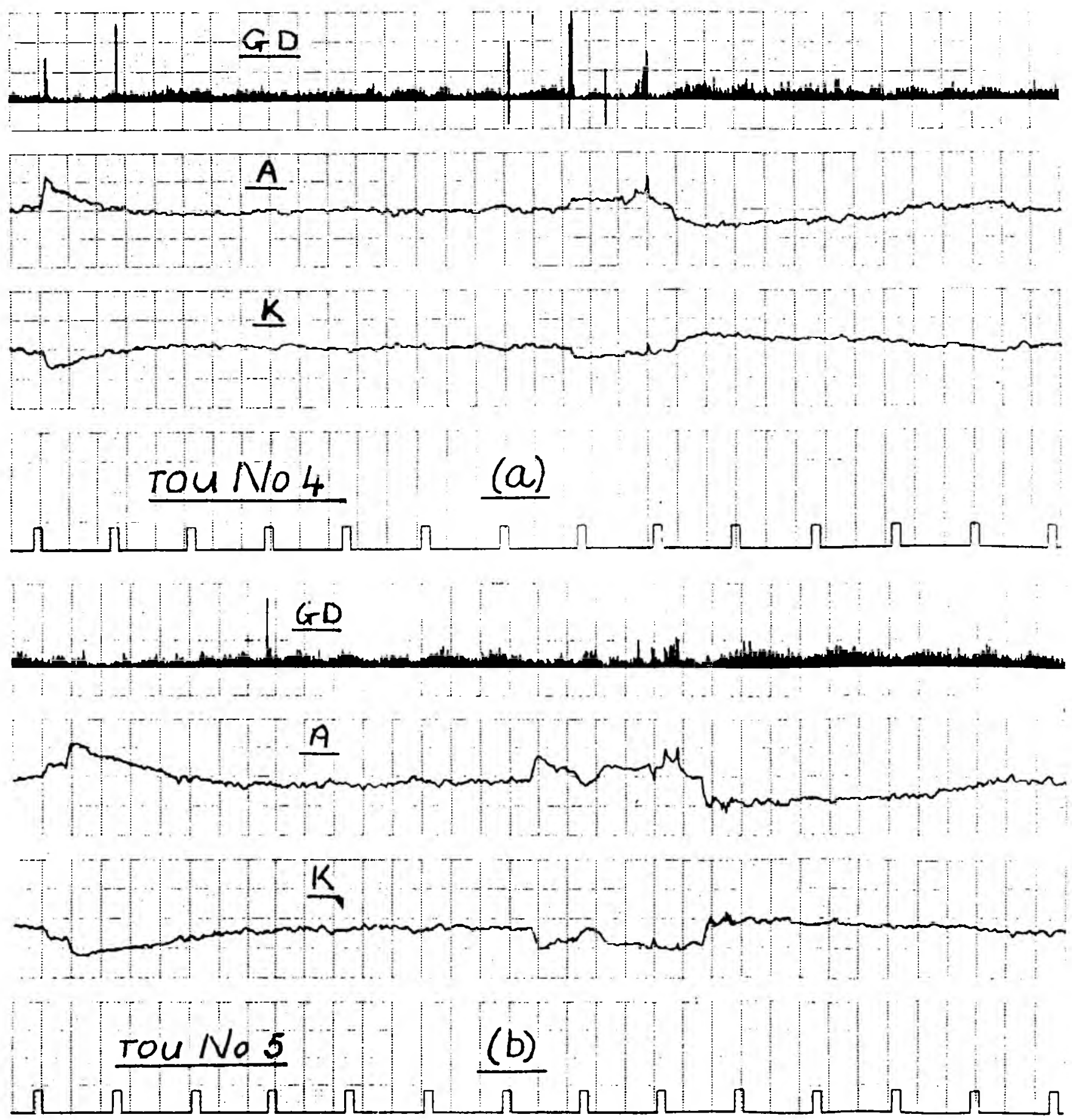

Figutur 12: Veldtoetse op twee geroeste toue. 
voer. Die toue het langs mekatr gehang en het lekens van inwendige roes oor dieselfde 90 meter lengtes getoon.

Enkele gebreekte drade kon op die omtrekoppervlaktes van die touc gesien word.

Fig. 12(a) en (b) wys dic meetresultate van tole nr. 4 en 5 onderskeidelik.

GI) is die gebrecktedraadmeetsein,

$A$ is dic oppervlaktemeetsein (dic polariteil is omgekecrd).

$\mathrm{K}$ is dic kontakmeetsein.

Die pulse op die vierde meetsein stel 10 meter toulengles voor.

Rocs:

(i) Roes vreet die drade weg. Mettertyd ontwikkel daar deursneeoppervakteveranderinge by roesplekke.

(ii) Roes self is nie elektries konduktief nie en vorm insulerende lac tussen die drade waar roes die drade weggevreet het. Konlak veranderinge kom dus by roesplekke voor.

(iii) As die roes erg ralak, vorm die roeskepe magnetiese dipole wat op die gebreckledraladmeetsein opgespoor word.

Fig. 12 toon die roes oor die 90 meter toulengtes op al drie die meetseine duidelik alan.

\section{Gevolgtrekking}

Die verslag beskryf 'n nuwe metode om gelyktydig en onafhank lik van mekaar die staaldeursneeoppervlakte van mynhystoue en veranderinge in die laterale kontak patroon tussen die drade van die tou te meet en om mel dieselfde instrument gebreckte drade daarin op te spoor.

\section{Verwysings}

1. Semmelink. A. (Julie 1956). Electromagnetic Testing of Wire Ropes, Trams. S.A. Inst. Elect. Engrs. $208-243$

2. Harvey, T. \& Kruger, H. W. (Junie 1959). The Theory and Practice of Electronic Testing of Winding Ropes, Trans. S.A. Inst. Elect. Engrs., 126-180

3. Otto, A. (1933). Elektromagnetishes Verfahren zur Prüfung von Drahtseiling, Glickcntf, 69, 47l-475.

4. Wall, T. F, \& Hainsworth. (1932). The Penetration of Alternating Magnetic Flux in Wire Ropes, $J$. Inst. Elect. Engrs. ( Brit). 71, 374-379.

5. Van der Walt. N. T. (1988). Dic Elektromagnetiese Toctsing van Staaltouc met behulp van Permanente Magnete, D. Ing. Proefskrif, Randse Afirikanase Universiteit, 1-200 